\title{
COVID-19 and Pembrolizumab-Induced Secondary Hemophagocytic Lymphohistiocytosis: a Case Report
}

\author{
Luis Ramos-Ruperto ${ }^{1}$ (D) - Carmen Busca-Arenzana ${ }^{1} \cdot$ Juan Valdivieso $^{2} \cdot$ Eduardo López-Granados $^{2}$. \\ Ángel Robles-Marhuenda ${ }^{1}$
}

Accepted: 25 March 2021 / Published online: 2 April 2021

(C) The Author(s), under exclusive licence to Springer Nature Switzerland AG 2021

\begin{abstract}
Our case highlights SARS-CoV-2 and pembrolizumab as trigger of secondary hemophagocytic lymphohistiocytosis. Although it is a rare complication, it must be suspected in order to start specific treatment. In this context, intravenous immunoglobulins could be a therapeutic option.
\end{abstract}

Keywords Hemophagocytic lymphohistiocytosis $\cdot$ Hemophagocytic syndrome $\cdot$ Pembrolizumab · COVID-19 · SARS-CoV-2

\section{Introduction}

The 2019 novel coronavirus disease (COVID-19), caused by SARS-CoV-2 infection, still remains a global health problem. Approximately, 5\% of patients suffer from the COVID-19 severe form consistent in the development of an immunemediated acute respiratory distress syndrome (ARSD) [1]. A dysregulated immune response and the so-called cytokine storm syndrome (CSS) had been implied in the pathogenesis. Immunological profile of severe COVID-19 patients showed increase in proinflammatory cytokines as IL6, IL10, TNF- $\alpha$, IL8, and IL10 and decrease of T CD4 and T CD8 lymphocytes [2]. This inflammatory profile, together with clinical characteristics of severe COVID-19 as fever, acute phase reactants, and ferritin elevation, resembled in part to hemophagocytic lymphohistiocytosis (HLH), where cytokine storm also has an important role. HLH is an hyperinflammatory CSS mainly mediated by aberrant $\mathrm{T}$ cell response. HLH may be primary due to specific genetic mutations or secondary (sHLH) to infections, neoplasm, or autoimmune disorders [3]. Viral infection is the main trigger for sHLH in adults, and some cases of sHLH related to COVID-19 have been described [4]. Several therapeutic alternatives had been proposed since the

This article is part of the Topical Collection on COVID-19

Ángel Robles-Marhuenda aroblesmarhuenda@gmail.com

1 Internal Medicine Department, Hospital La Paz, Madrid, Spain

2 Immunology Department, Hospital La Paz, Madrid, Spain beginning of the pandemic caused by COVID-19, among them are checkpoint inhibitors directed against PD1/PDL1 as they may mitigate lymphocyte exhaustion and defective activation of T lymphocyte caused by SARS-CoV-2 infection [2]. We present the case of a patient under treatment with anti-PD1 antibodies infected by SARS-CoV-2 who develop sHLH and was successfully treated with intravenous immunoglobulins (IVIG).

\section{Case Report}

A 76-year-old man undergoing treatment with anti-PD1 antibody (pembrolizumab) for lung adenocarcinoma consulted in the Emergency Department for fever and 1 week of dyspnea. Physical examination revealed peripheral oxygen saturation < $90 \%$, requiring supplemental oxygen. No infiltrates were found on the chest X-ray, despite a positive polymerase chain reaction (PCR) for SARS-CoV-2 in nasopharyngeal swab. Initial blood test results are shown in Table 1. During admission, he received treatment with hydroxychloroquine and respiratory support for 10 days, being discharged upon resolution of fever and respiratory symptoms. Two weeks later, he returned to the hospital, due to high unremittent daily fever up to $39^{\circ}$. No clear etiology was evident in the anamnesis, and the physical examination was unremarkable, excepting the fever. Broad-spectrum antibiotics were initiated (meropenem, linezolid, and trimethoprim-sulfamethoxazole). Blood cultures were negative on several occasions; cytomegalovirus and Epstein-Barr virus viral loads were undetectable; serologies for syphilis, HIV, hepatitis B, hepatitis C, Mycoplasma 
Table 1 Clinical course and laboratory results

\begin{tabular}{|c|c|c|c|c|c|c|}
\hline \multirow[t]{2}{*}{ Timeline } & 13 March & 12 April & 17 April & \multirow[t]{2}{*}{$\begin{array}{l}19 \\
\text { April }\end{array}$} & 27 April & \multirow[t]{2}{*}{ Reference values } \\
\hline & $\begin{array}{l}\text { First visit to } \\
\text { Emergency }\end{array}$ & $\begin{array}{l}\text { Second visit to } \\
\text { emergency }\end{array}$ & $\begin{array}{l}\text { HLH suspected IGIV } \\
\text { started }\end{array}$ & & $\begin{array}{l}10 \text { days after } \\
\text { IVIG }\end{array}$ & \\
\hline PCR SARS-CoV-2 & Positive & Positive & & & Negative & \\
\hline Temperature $\left({ }^{\circ} \mathrm{C}\right)$ & 39 & 39 & 38 & & 36.3 & $<37$ \\
\hline Hemoglobin, g/dL & 13 & 11.4 & 10.6 & & 9.3 & $13.5-17.2$ \\
\hline $\begin{array}{l}\text { White blood cell count, per } \\
\mathrm{mm}^{3}\end{array}$ & 6000 & 4050 & 1800 & & 2830 & $3900-10,200$ \\
\hline Lymphocyte count, per $\mathrm{mm}^{3}$ & 190 & 150 & 0 & & 450 & $1100-4500$ \\
\hline Platelet count, per $\mathrm{mm}^{3}$ & 134,000 & 244,000 & 71,000 & & 193,000 & $150,000-370,000$ \\
\hline Fibribogen, mg/dL & 584 & 758 & 682 & & 615 & $150-450$ \\
\hline Triglycerides, mg/dL & & & 191 & & & $<150$ \\
\hline GOT, UI/L & 44 & 23 & 53 & & 22 & $<40$ \\
\hline Ferritin, ng/ml & & 542 & 3931 & & 1083 & $22-322$ \\
\hline Hepatomegaly & & & Yes & & No & \\
\hline Splenomegaly & & & Yes & & No & \\
\hline \multicolumn{7}{|l|}{ Cytokines } \\
\hline IL10, $\mu \mathrm{g} / \mathrm{ml}$ & & & 23.9 & & 4.85 & $1.77-3.76$ \\
\hline $\mathrm{IL} 2, \mu \mathrm{g} / \mathrm{ml}$ & & & Undetectable & & Undetectable & Undetectable \\
\hline IL17A, $\mu \mathrm{g} / \mathrm{ml}$ & & & 3.41 & & Undetectable & Undetectable \\
\hline IL4, $\mu \mathrm{g} / \mathrm{ml}$ & & & Undetectable & & Undetectable & Undetectable \\
\hline IL6, $\mu \mathrm{g} / \mathrm{ml}$ & & & 770 & 42 & 30.8 & $0.703-6.06$ \\
\hline IL1RA, $\mu \mathrm{g} / \mathrm{ml}$ & & & 20681 & & 825 & $225-682$ \\
\hline IFN gamma, $\mu \mathrm{g} / \mathrm{ml}$ & & & 172 & & 1.02 & $0.544-2.72$ \\
\hline TNF alpha, $\mu \mathrm{g} / \mathrm{ml}$ & & & 168 & & 18.4 & $7.78-12.2$ \\
\hline $\mathrm{CD} 25 \mathrm{sol}, \mu \mathrm{g} / \mathrm{ml}$ & & & 14363 & & 4671 & $580-1660$ \\
\hline $\mathrm{CD} 163, \mathrm{ng} / \mathrm{ml}$ & & & 5883.901 & & 2602.837 & $201.13-826.68$ \\
\hline
\end{tabular}

pneumoniae, Coxiella burnetti, and Parvovirus B19 were negative; and Interferon Gamma Release Assay (IGRA) tested negative. However, SARS-CoV-2 PCR remained positive in the nasopharyngeal swab. Despite antibiotic treatment, daily fever persisted, and clinical and analytical parameters worsened presenting pancytopenia, organomegaly, and elevation of ferritin and cytokine profile (Table 1). A positron emission tomography performed was unremarkable. At that point, calculated Hscore score was 211 , conferred a $93.65 \%$ probability of his clinical condition being caused by hemophagocytic lymphohistiocytosis [5]. Bone marrow examination was not obtained. High-dose intravenous immunoglobulins (IVIG) (1 $\mathrm{g} / \mathrm{Kg} \times 2$ days) were started, with fever disappearance, hemodynamic improvement, and attenuation of acute phase reactants (Table 1). The patient improved and was discharge without presenting recurrence in the follow-up.

\section{Discussion}

HLH and cytokine storm syndrome related to severe COVID19 (COVID-19-CSS) had some characteristics in common, including the presence of hemophagocytosis [4, 6]. However, COVID-19-CSS has predominant pulmonary affectation, and trends to have less ferritin elevation and organomegaly and pancytopenia are not frequent $[7,8]$ (Table 2).

Many articles published so far have tried to answer the question of the prevalence of HLH in COVID-19 disease and if it is linked to COVID-19-CSS. Hscore was initially design for evaluation of secondary HLH [5] and had not performed well as a risk score tool in COVID-19 [9]. The presence of hemophagocytosis in different tissue samples was not specific of HLH in COVID-19 autopsies [4]. However, Hscore was more elevated in patients diagnosed of HLH in the context of COVID-19 than in the rest of critical COVID19 patients [4, 10]. Prevalence of HLH in COVID-19 varies from 2 to $17 \%$ among series $[10,11]$. Nevertheless, several case reports and case series had reported SARS-CoV-2 as a trigger of secondary HLH [12]. What made us lean towards the diagnosis of HLH in our patient was the presence of severe pancytopenia and organomegay. Also, pre- and post-IVIG sera were evaluated retrospectively for a set of cytokines typically associated with COVID-19-CSS (Table 1). Elevation of several pro-inflammatory cytokine and factors was evidenced 
Table 2 Differences between secondary HLH and CSS related COVID-19

\begin{tabular}{ll}
\hline sHLH & CSS-related COVID-19 \\
\hline Fever & Fever \\
$\uparrow \uparrow$ Ferritin & $\uparrow$ Ferritin \\
Pancytopenia & Lymphopenia, thrombopenia \\
$\uparrow$ AST & $\uparrow$ AST \\
Hemophagocytosis in biopsy & Hemophagocytosis in biopsy \\
Hepatomegaly, splenomegaly & ARDS \\
$\downarrow$ Fibronogen & $\uparrow$ Fibrinogen \\
$\uparrow$ Triglycerides & $\mathrm{N} / \uparrow$ Triglycerides
\end{tabular}

$A S T$ aspartate aminotransferase, ARDS acute respiratory distress syndrome, CSS cytokine storm syndrome, $s H L H$ secondary hemophagocytic lymphohistiocytosis, $N$ normal

not fully resembling the phenotype described in COVID-19CSS [13]. In this line, IVIG treatment induced a tempering of cytokines levels measured before and after its infusion.

One interesting point is the fact that this patient was under treatment with pembrolizumab, an anti-PD1 antibody. PD1/ PDL1 immune checkpoint inhibitors, widely used in cancer therapy, had been proposed as treatment of COVID-19 because of their potential to revert the lymphocyte exhaustion and defective activation of $\mathrm{T}$ cells promoted by SARS-CoV-2 [14]. Treatment with PD-1 checkpoint inhibitors induce an immune-modulated state characterized by a non-specific immune activation, mainly due to the blocking of PD-1 in T lymphocytes, especially CD8+ [15]. Anti-PD-1 treatment during COVID-19 infection has been reported safely in oncologic patients $[16,17]$. However, an association between immune checkpoint inhibitors treatment and sHLH had been well described in literature [18]. This set the hypothesis that treatment with pembrolizumab in this patient had probably contributed to the development of SHLH in concurrence with SARS-CoV2 infection. Secondary hemophagocytic lymphohistiocytosis may appear in the context of COVID-19 infection, even more if the patient is under treatment with anti PD1/PDL1 checkpoint inhibitors; clinicians must be awarded in order to initiate specific treatment.

Code Availability Not applicable.

Author Contribution All authors have contributed in the redaction, revision, and correction of the manuscript.

Data availability Not applicable, as is a case study report.

\section{Declarations}

Ethics Approval The Ethics Committee of the Hospital Universitario La Paz waived the need for ethics approval for this non-interventional study.
Consent to Participate Not applicable, as there was no intervention. Patient informed consent was obtained for the publication of the manuscript.

Competing Interests The authors declare no competing interests.

\section{References}

1. Zhou F, Yu T, Du R, Fan G, Liu Y, Liu Z, et al. Clinical course and risk factors for mortality of adult inpatients with COVID-19 in Wuhan, China : a retrospective cohort study. Lancet. 2020;395: 1054-62. https://doi.org/10.1016/S0140-6736(20)30566-3.

2. Tang Y, Liu J, Zhang D, Xu Z, Ji J, Wen C. Cytokine storm in COVID-19: the current evidence and treatment strategies. Front Immunol. 2020;11:1-13. https://doi.org/10.3389/fimmu.2020. 01708.

3. Ramos-Casals M, Brito-Zerón P, López-Guillermo A, Khamashta MA, Bosch X. Adult haemophagocytic syndrome. Lancet. 2014;383:1503-16. https://doi.org/10.1016/S0140-6736(13) 61048-X.

4. Prilutskiy A, Kritselis M, Shevtsov A, Yambayev I, Vadlamudi C, Zhao Q, et al. SARS-CoV-2 infection-associated hemophagocytic lymphohistiocytosis an autopsy series with clinical and laboratory correlation. Am J Clin Pathol. 2020;154:466-74. https://doi.org/10. 1093/AJCP/AQAA124.

5. Fardet L, Galicier L, Lambotte O, Marzac C, Aumont C, Chahwan $\mathrm{D}$, et al. Development and validation of the hscore, a score for the diagnosis of reactive hemophagocytic syndrome. Arthritis Rheumatol. 2014;66:2613-20. https://doi.org/10.1002/art.38690.

6. Debliquis A, Harzallah I, Mootien JY, Poidevin A, Labro G, Mejri A, et al. Haemophagocytosis in bone marrow aspirates in patients with COVID-19. Br J Haematol. 2020;190:e70-3. https://doi.org/ 10.1111/bjh.16860.

7. Hakim NN, Chi J, Olazagasti C, Liu JM. Secondary hemophagocytic lymphohistiocytosis versus cytokine release syndrome in severe COVID-19 patients. Exp Biol Med. 2020;246:15. https://doi.org/10.1177/1535370220962043.

8. Lorenz G, Moog P, Bachmann Q, La Rosée P, Schneider H, Schlegl M, et al. Title: Cytokine release syndrome is not usually caused by secondary hemophagocytic lymphohistiocytosis in a cohort of 19 critically ill COVID-19 patients. Sci Rep. 2020;10:1-11. https://doi.org/10.1038/s41598-020-75260-w.

9. Clark KEN, Nevin WD, Mahungu T, Lachmann H, Singh A. Assessment of the hemophagocytic lymphohistiocytosis HScore in patients with coronavirus disease 2019. Clin Infect Dis. 2020. https://doi.org/10.1093/cid/ciaa1463.

10. Yang K, Xing M, Jiang L, Cai Y, Yang L, Xie N, et al. Infectionassociated hemophagocytic syndrome in critically ill patients with COVID-19. Curr Med Sci. 2021;41:39-45. https://doi.org/10.1007/ s11596-021-2315-4.

11. Hueso T, Bouchez C, Salviat F, Foulon S, Albiges L, Bayle A, et al. Secondary haemophagocytic lymphohistiocytosis is a rare occurrence amongst cancer patients with COVID-19. Br J Haematol. 2021;192:e87-90. https://doi.org/10.1111/bjh.17275.

12. Retamozo S, Brito-Zerón P, Sisó-Almirall A, Flores-Chávez A, Soto-Cárdenas MJ, Ramos-Casals M. Haemophagocytic syndrome and COVID-19. Clin Rheumatol. 2021;40:1233-44. https://doi. org/10.1007/s10067-020-05569-4.

13. Qin C, Zhou L, Hu Z, Zhang S, Yang S, Tao Y, et al. Dysregulation of immune response in patients with coronavirus 2019 (COVID-19) in Wuhan. China. 2019;2020:4-10. https://doi.org/10.1093/cid/ ciaa248. 
14. Diao B, Wang C, Tan Y, Chen X, Liu Y, Ning L, et al. Reduction and functional exhaustion of $\mathrm{T}$ cells in patients with coronavirus disease 2019 (COVID-19). Front Immunol. 2020;11. https://doi. org/10.3389/fimmu.2020.00827.

15. Kamphorst AO, Pillai RN, Yang S, Nasti TH, Akondy RS, Wieland A, et al. Proliferation of PD-1+CD8 T cells in peripheral blood after PD-1-targeted therapy in lung cancer patients. Proc Natl Acad Sci. 2017;114:4993-8. https://doi.org/10.1073/pnas.1705327114.

16. Pala L, Conforti F, Saponara M, De Pas T, Giugliano F, Omodeo Salè E, et al. Data of Italian Cancer Centers from two regions with high incidence of SARS CoV-2 infection provide evidence for the successful management of patients with locally advanced and metastatic melanoma treated with immunotherapy in the era of COVID-19. Semin Oncol. 2020;47:302-4. https://doi.org/10. 1053/j.seminoncol.2020.07.010.
17. Bersanelli M, Zielli T, Perrone F, Casartelli C, Prattico F, Rapacchi E, et al. Clinical impact of COVID-19 in a single-center cohort of a prospective study in cancer patients receiving immunotherapy. Immunotherapy. 2020;12:1139-48. https://doi.org/10.2217/imt2020-0211.

18. Noseda R, Bertoli R, Müller L, Ceschi A. Haemophagocytic lymphohistiocytosis in patients treated with immune checkpoint inhibitors: analysis of WHO global database of individual case safety reports. J Immunother Cancer. 2019;7:1-6. https://doi.org/ 10.1186/s40425-019-0598-9.

Publisher's Note Springer Nature remains neutral with regard to jurisdictional claims in published maps and institutional affiliations. 